\title{
Logophoric Centers as Antecedents of NOC PRO: Evidence from Turkish Subject Infinitives
}

\author{
Duygu Göksu*
}

\begin{abstract}
This paper questions the mechanism behind the control structure observed in subject infinitival clauses in Turkish. After comparing the main points of the proposals in the Movement Theory of Control in Boeckx, Hornstein, and Nunes (2010), pragmatics based Non-Obligatory Control analysis in Landau (2013) and the UPro Approach in McFadden and Sundaresan (2016), I conclude with the claim that these are logophoric center sensitive NOC structures.
\end{abstract}

Keywords. control; infinitives; NOC; OC; PRO; pro; pro-drop; Turkish

1. Introduction. Control constructions in Turkish are non-finite clauses formed with the infinitival nominalizer $-\mathrm{mA}(\mathrm{K})$. So far studies on Turkish control structures have focused mainly on the derivation of clauses that exhibit obligatory control (OC) like in (1) (Aydin, 2005; Kornfilt, 1984; Oded, 2006; Oded and Öztürk, 2008; Özsoy, 1987).
(1) Ayşe ${ }_{i}$
$\left[\mathrm{PRO}_{\mathrm{i}}\right.$ ev-e gel-mek] iste-di.
Ayşe-NOM home-DAT come-INF want-PST.3.SG
'Ayşe wanted to come home.'

This paper focuses on those such as in (2) that occur in the subject position of a sentence.

(2) $\quad\left[\mathrm{PRO}_{i}\right.$ yürü-mek] Alii-yi sevin-dir-di. walk-INF Ali-ACC be.happy-CAUS-PST.3.SG

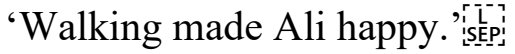

In (2) above, Ali is the experiencer of the matrix event and $P R O$ is obligatorily co-referential with it. In the absence of such an experiencer, $P R O$ gets arbitrary reading as in (3).

(3) $\left[\mathrm{PRO}_{\text {arb }}\right.$ vegan ol-mak $]$ gezegen için iyi.

vegan be-INF planet for good

'Being vegan is good for the planet.'

The crucial difference of interest here between the English counterparts of these structures and those in Turkish is that in English the controller is ambiguous between the sentence topic and the logophoric center (i.e. the object experiencer) of the sentence, as shown in (4).

(4) As for Mary,$\left[\mathrm{PRO}_{\mathrm{i} / \mathrm{j}(+\mathrm{i})}\right.$ quitting the race] upset her teammate $\mathrm{John}_{\mathrm{j}}$.

In the Turkish counterpart of (4) given in (5), the controller can only be the logophoric center Ali.

\footnotetext{
* This is based on a chapter in my MA Thesis. I am truly grateful to the students and professors at the Boğaziçi University Linguistics Department for their contributions. I am especially thankful to Elena Guerzoni, Martina Gračanin-Yüksek, and my advisor Balkız Öztürk. Also, I thank the attendants of the syntax workshop at UMass. I am thankful to Kyle Johnson, Rajesh Bhatt, Kaden Holladay, Deniz Özyıldız, and Alex Nyman for their feedback. Author: Duygu Göksu, University of Massachusetts Amherst (dgoksu@umass.edu).
} 
(5) Ayşe-ye ${ }_{i}$ gelince, $\left[\mathrm{PRO} *_{\mathrm{i} / \mathrm{j}(+\mathrm{i})}\right.$ yarış-tan çekil-mek] takım arkadaşı Ali-yi $\mathrm{i}_{\mathrm{j}}$ üz-dü.

Ayşe-DAT AS.FOR race-ABL quit-INF team mate Ali-ACC upset-PST.3.SG

'As for Ayşe, (him/them) quitting the race upset her teammate Ali.'

As indicated by the ' $+\mathrm{i}$ ' index in parenthesis, split control of the PRO by both Ali and Ayşe is possible, which is also possible in (4). What is crucial is that co-indexation only with Ayşe is not allowed. For the empty subject to co-refer with the sentence topic Ayşe, the embedded infinitive needs to bear possessive agreement, as shown in (6), which means that the structure is no more a control infinitive with a PRO subject.

(6) Ayşe-ye e $_{\mathrm{i}}$ gelince, [pro $\mathrm{i} / \mathrm{j}$ yarış-tan çekil-me-si] takım arkadaşı Ali-yij $\ldots$

Ayşe-DAT as.for race-ABL quit-INF-POSS.3.SG team mate Ali-ACC

'As for Ayşe, (her) quitting the race upset her teammate Ali.'

For the English counterparts of these constructions, Boeckx, Hornstein, and Nunes (2010) put forward a movement-based Obligatory Control (OC) analysis, while Landau (2013) claims that these are Non-Obligatory Control (NOC) structures where the controller of the null subject PRO is either the logophoric center or the sentence topic. I will argue that the Turkish data pose a challenge to Boeckx et al. (2010) and cannot be derived as cases of movement-based OC constructions. I will show that these structures are accounted for better under Landau's (2013) approach, yet it does not fully pattern with English, where either logophoricity or topicality can have an effect in the NOC relation. I will show that Turkish exhibits a more restricted pattern where only logophoricity can build the NOC relation; topicality does not suffice. I will conclude that the small pro and NOC PRO distribution supports the UPro approach in McFadden and Sundaresan (2016) as the two empty subjects NOC PRO and pro in subject clauses come with two different structures, the latter but not the first coming with agreement on the embedded verb.

The rest of the paper is organized as follows. In section 2, I provide a summary of the movement based account of Boeckx et. al. (2010) and present data that suggest these are not movement based Obligatory Control relations. In section 3, I go over Landau's (2013) analysis of Non-Obligatory Control structures in English and show that topicality is not relevant the same way it is in English for the control structure observed in subject infinitives in Turkish. In addition, I present the mechanism McFadden and Sundaresan (2016) propose for deriving the three embedded subjects: OC PRO, NOC PRO, and small pro from the underlying UPro element based on the syntactic environment they appear in. Then, in section 4, I conclude with the proposal that small pro and NOC PRO in subject infinitives support this analysis with their somewhat split syntactic environment, but the agreement bearing infinitival environment of the small pro is an addition to the 'fully-finite' clauses they identify.

\section{Is it a movement based OC relation?}

2.1. MOVEMENT THEORY OF CONTROL In BOECKX, HoRnSTEIn, AND NunEs (2010). In the Movement Theory of Control of Boeckx, Hornstein, and Nunes (2010), the PRO/trace subject in an OC relation is a result of movement and NOC is seen as the elsewhere situation which makes use of a small pro subject.

Following Boeckx and Hornstein (2007), according to Boeckx et al. (2010), "The distribution of PRO and small pro is a dual function of the grammar and the parser" (p. 209). A wellbehaved parser is added to the system, in addition to an economy preference of the grammar governing the choice between PRO and small pro proposed in Hornstein (2001, 2003, 2007). 
The following assumptions are made regarding the parsers that drop one of the two empty categories to a phonetic gap:

(7) a. Parsers move from left to right and project structure rapidly and deterministically on the basis of local information.

b. Parsers are transparent with respect to grammars. So, if grammars encode a condition, parsers respect it.

c. Parsers are interpretively greedy.

Consequently, given that grammars prefer movement to pronominalization, a phonetic gap in a given sentence is treated as a PRO/trace rather than a pro whenever possible, which makes the relationship OC. A prediction that MTC makes when there are two antecedents to the right of the gap and there is no movement constraint between the position of the phonetic gap and one of the antecedent DPs is that the parser drops a PRO/trace that is co-indexed with this DP and the relationship obtained is $\mathrm{OC}$, as in (8).

$\left[\mathrm{PRO}_{\mathrm{i} / *_{\mathrm{j}}}\right.$ having to wash behind the ears $]$ made Mary $\mathrm{i}$ angry at Bill ${ }_{\mathrm{j}}$.

Since pro is not preferred by the grammar, and movement between the position of Bill and the embedded subject position is not allowed, the only way for the embedded subject to refer to Bill is to have an overt pronoun instead of a null subject, as shown in (9).

(9) $\left[\mathrm{Him}_{\mathrm{i}}\right.$ having to wash behind the ears $]$ made Mary angry at Bill ${ }_{\mathrm{i}}$.

Also, MTC treats OC and NOC as relations, but not as structures. As shown in (10a-b), two very similar sentences can allow OC or NOC depending on which R-expression the null element ends up co-referring with.

(10) a. John $n_{i}$ said that PRO $*_{i j}$ washing herself delighted Mary ${ }_{j}$.

b. John ${ }_{i}$ said that pro $_{i} / *_{j}$ washing himself delighted Maryj.

In (10a), what is claimed is an OC relation built via the movement of the embedded direct object Mary, whereas in (10b) a pro occupies the same - subject of the embedded subject clause - position that is in an NOC relation with the matrix subject John to the position of which movement is not licit. Here, the first preference builds an NOC relation while the second one builds an OC. Since both options have advantages, both outcomes are grammatical.

What is crucial for us, PRO/trace is argued to be a result of sideward movement, which proceeds via copy and merge of Mary as illustrated in (11), from Boeckx et al. (2010, p. 201).

Select and merge:
Copy and merge (sideward $m v$.):
Merge:
Deletion at PF:

[Mary washing herself] delighted.

[Mary ${ }_{i}$ washing herself] [delighted Maryi]

[[Maryi washing herself] delighted Maryi]

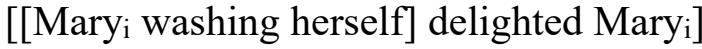

2.2. TURKISH PRO vs. pro: CONTROL VS. No CONTROL. Differently from English, in Turkish the distinction of the two null arguments pro and PRO is morphologically encoded on a verb via the presence or absence of agreement, respectively. Since it is a pro-drop language, Turkish allows dropping an overt pronoun and replacing it with a pro when the verb is inflected for person for the subject as given in (12). 
(12) Ben $_{\mathrm{i}} / \mathrm{pro}_{\mathrm{i}}$ gel-dim.

I.NOM come-PST.1.SG

'I came.'

In addition to finite clause subjects, embedded genitive subjects can be dropped and replaced with a small pro when the embedded predicate bears possessive agreement, thus carrying the person inflection of the dropped subject. Example in (13a) illustrates these cases of nocontrol structures as opposed to control structures that come with a bare predicate and a PRO subject as in (13b).
a. $\mathrm{Ali}_{\mathrm{i}} \quad\left[\mathrm{o}-\mathrm{nun}_{\mathrm{j}} / \mathrm{pro}_{\mathrm{j}}\right.$ git-me-sin]-i
iste-di.
Ali-NOM he-GEN leave-INF-POSS.3.SG-ACC want-PST.3.SG
'Ali wanted him to leave.'
b. $\mathrm{Ali}_{\mathrm{i}} \quad\left[\mathrm{PRO}_{\mathrm{i}}\right.$ git-mek $]$ iste-di.
Ali-NOM leave-INF want-PST.3.SG
'Ali wanted to leave.'

The following data set exemplifies cases where the MTC fails to predict the co-occurrence of both PRO and small pro. As we have seen in the English example in (5), when both DPs are to the right of the phonetic gap, there is no motivation for dropping a pro subject as movement is licit and so a PRO/trace which is co-indexed with Mary is preferred by the grammar. However, the possible interpretations of the gap that (14a) and (14b) illustrate indicate that structures involving both PRO and pro are grammatical in Turkish.

a. $\left[\mathrm{PRO}_{\mathrm{i} /{ }^{*} \mathrm{j}}\right.$ hep bulaşı $1 \mathrm{k}$ yka-mak] Ahmet $\mathrm{A}_{\mathrm{i}} \mathrm{i} \quad \mathrm{Ali}_{\mathrm{j}}$-den soğut-tu always dishes wash-INF Ahmet-ACC Ali-ABL alienate-PST.3.SG

'Always washing the dishes alienated Ahmet from Ali.'

b. [pro $\mathrm{p}_{\mathrm{i} j \mathrm{j}}$ hiç bulaşık yıka-ma-ma-si] Ahmet $\mathrm{j}-\mathrm{i}$

never dishes wash-NEG-INF-POSS.3.SG Ahmet-ACC

Ali $_{i}$-den soğut-tu.

Ali-ABL alienate-PST.3.SG

'His never washing the dishes alienated Ahmet from Ali.'

MTC would only predict the grammaticality of (14a) as movement is claimed to be possible between the positions of PRO/trace and Ahmet. In (14b), the possibility of dropping a pro subject co-indexed with Ali or Ahmet is not predicted by MTC.

Secondly, if the PRO subject in the embedded subject position is a leftover of movement as the MTC claims it to be, it is expected to exhibit only exhaustive control (EC) with its antecedent, as the element that moved (i.e. the controller) would have to be identical to its trace (i.e. PRO). However, the following examples of Turkish subject infinitival clauses given in (15a) and (15b) show that it is possible for this $P R O$ to be in split control (SC) or partial control (PC) relations, respectively.

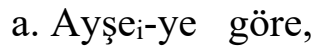 $\left[\mathrm{PRO}_{\mathrm{i}+\mathrm{j}}\right.$ çift ol-mak] Ali $\mathrm{j}$-yi Ayşe-DAT according.to couple be-INF Ali-ACC mutlu et-ti. happy make-PST.3.SG 'According to Ayşe, being a couple made Ali happy.' 
b. $\left[\mathrm{PRO}_{\mathrm{i}+}\right.$ o kafe-de toplan-mak] $\mathrm{Ali}_{\mathrm{i}-\mathrm{yi}}$ mutlu et-ti. that café-LOC meet-INF Ali-ACC happy make-PST.3.SG

'Meeting at that café made Ali happy.'

The possibility of PC and SC in fact signals not a movement-based, but a movement- free analysis for the subject clauses. Thus, I claim that the subject clause must be base-generated in the matrix subject position. I follow the theta hierarchy proposed in Pesetsky (1995), given here in (16a), wherein the highest-ranked argument is linked to the highest syntactic position in the clause that contains it, as in (16b) and (16c).
a. Causer $>$ Experiencer $>$ Subject Matter /Target
b. [VP Causer [V'V Experiencer]]
c. [VP Experiencer [V'V Subject Matter/Target]]

\section{Is it a case of Non-Obligatory Control?}

3.1. NOC IN LANDAU (2013). Landau (2013) also proposes that OC is built via grammatical processes, and that where OC is not possible, NOC applies as the elsewhere case. The following distributional distinction is proposed:

(17) Complement clauses fall under OC; subject and adjoined clauses fall under NOC.

As the elsewhere situation, (18a) and (18b) are examples of NOC in English in the form of a subject and an adjoined (extraposed) clause respectively.

(18) a. $\mathrm{John}_{\mathrm{i}}$ finally realized that $\left[\mathrm{PRO}_{\mathrm{i}+\mathrm{j}}\right.$ hurting each other] really bothered $\mathrm{Sue}_{\mathrm{j}}$.

b. I never understood why it is bad for health $\left[\mathrm{PRO}_{\mathrm{arb}}\right.$ to stuff oneself with marshmallows].

The NOC signature is defined as given in (19).

(19) In a control construction [...[s PRO...]...]:

a. The controller need not be a grammatical element or a co-dependent of S.

b. PRO needs not be interpreted as a bound variable (i.e., it may be a free variable).

c. PRO is [+human].

So, NOC is established based on a logophoric center- or topicality-based pragmatic relation with a [+human] controller. Logophoric centers are the subjects and objects of mental verbs (e.g., think, realize), psychological predicates (e.g., disturb, angry), and communication verbs (e.g., tell, hear). When there is a logophoric center in the event, the event is perceived from the mental state of the participant that constitutes the logophoric center.

In addition to logophoric centers, Landau (2000) identifies a class of transparent nouns that allow NOC from within. Landau (2013) states that nouns of this class denote "abstract notions that reflect the individuality of the controller via actions, character traits or social attributes" (p. 248). Career is one such example, as (20) shows, among others such as status, confidence, image, success, fear, hope, etc.

(20) $\left[\mathrm{PRO}_{\mathrm{i}}\right.$ causing an uproar $]$ is important for John's $\mathrm{s}_{\mathrm{i}}$ career.

Accordingly, for an NP to function as the logophoric extension of $\mathrm{X}$ in a given NOC structure where we have $X$ 's $N P, \mathrm{~N}$ needs to be an inalienably possessed noun. This is what is happening in (20) above. 
The next condition in NOC that Landau (2013) puts forward is topicality. Namely, "the antecedent of NOC PRO must be the discourse or the sentence topic." This antecedent does not necessarily need to be topicalized, but like all topics, it must be old information. Since indefinite DPs introduce new individuals to the context, they are not suitable controllers, as the following example shows.

(21) [After $\mathrm{PRO}_{i}$ collecting some money], a bank account was opened by the landlord $_{\mathrm{i}} / *$ by a businessman ${ }_{\mathrm{i}}$.

While the definite DP the landlord can control the PRO in the preceding adjunct clause, the indefinite DP a businessman is not a licit controller for the same $P R O$. The following example tests the [+human] restriction to see if a nonhuman topic can be the controller in NOC.

(22) As for the boots $\mathrm{s}_{\mathrm{i}}$, it was obvious [that for them $\mathrm{i} /{ }^{*} \mathrm{PRO}_{\mathrm{i}}$ to be produced in Italy] would increase their appeal.

Here, the boots is introduced as the sentence topic, but since it is nonhuman, it fails to control the $P R O$ in the embedded clause. Thus, Landau concludes that [+human] is a necessity for the NOC controller. Landau also raises the question of whether or not the two restrictions topicality and logophoricity are independent of each other. In (23), a [+human] topic different than the logophoric center is introduced to see whether it can be the controller in NOC.

(23) All I can say about Maryi is that most people I have spoken with agree that while [ $\mathrm{PRO}_{\mathrm{i}}$ removing herself from the race so quickly] may have pleased the party hacks, it will surely distress the people whose interests she represents.

Here, Mary is a [+human] referent introduced as the topic, and although the logophoric center is the DP the party hacks as the object of please, Mary is claimed to be the controller. The feedback I received for the sentence in (23) regarding the judgments is that the PRO subject can be controlled by either DP, as I have shown earlier in example (4), repeated here in (24).

(24) As for Mary, $\left[\mathrm{PRO}_{\mathrm{i} j(\mathrm{i})}\right.$ quitting the race] upset her teammate $\mathrm{John}_{\mathrm{j}}$.

What is important is that the topic can also control the PRO. To conclude, according to Landau (2013), NOC is a pragmatic phenomenon the conditions of which are as given in (25).

(25) In an NOC configuration $[\ldots$... DP ... [PRO ... ] ... ] (order irrelevant), the DP may control PRO iff it is [+human] and either a logophoric center or topic-oriented.

This definition makes the [+human] restriction a necessity, while logophoricity and topicality are each independently sufficient.

3.2. UPRO APPROACH IN MCFADDEN \& SUNDARESAN (2016). Their proposal is as follows: There is a single element UPro as the underlying form of PRO in Obligatory and Non-Obl. Control and pro. It starts with an unvalued $\mathrm{F}$ feature. The different interpretations of UPro are the results of what happens to this F. Thus, it is purely dependent on the local syntactic environment where it surfaces. Specifically, when UPro is in a position where structural control (i.e. OC) can apply, it does so obligatorily. This values F via Agree with an antecedent and derives the bound variable interpretation. When such control fails, the less specific interpretations - pro and NOC PROmay be derived, or $\mathrm{PRO}_{a r b}$ arises as the elsewhere case. They identify three environments where OC does not apply: 
(26) a. Prototypical finite clauses,

b. A root clause or

c. A clause functioning as the subject of a matrix clause

So OC is conditionally obligatory but fallible. As for the conditions for the other two variants of UPro, their conditions are as given in (27a-b).

(27) a. Definite pro: A fully finite clause will contain the representation of a topic in its left periphery (Frascelli, 2007: silent pos. for topic in the left periphery) allowing the UPro to get a definite pro interpretation via Agree.

b. NOC PRO: Likewise, the "perspective-holder" in the left periphery (Speas 2004, Giorgi 2010, Sundaresan 2012) will value the F feature on UPro allowing it to get an NOC PRO interpretation.

To summarize, NOC PRO gets its referent from the logophoric center of the event denoted in the sentence while small pro is co-referent with the sentence topic. Both the topic and the perspective holder reside in silent positions in the left periphery.

\section{Proposal: It is Logophoric Center Sensitive NOC}

4.1. LOGOPHORIC CENTERS AND EXTENSIONS AS CONTROLLERS. As proposed for English by Landau (2013), inalienably possessed abstract and concrete nouns can behave as logophoric extenders and the NP inside this phrase can control the PRO in the subject infinitive in Turkish, as the contrast in (28a-b) shows.

a. $\left[\mathrm{PRO}_{\mathrm{i}} \mathrm{s} 1 \mathrm{k}\right.$ sık duş al-mak] Ali ${ }_{i}$-nin saçlar-1 için iyi değil. frequently shower take-INF Ali-GEN hair-POSS.3.SG for good not '(Him) frequently taking showers is not good for Ali's hair.'

b. *[PRO $\mathrm{P}_{\mathrm{i}} \mathrm{k}$ k sik duş al-mak] Alii-nin banyo-su için iyi değil. frequently shower take-INF Ali-GEN bathroom-POSS.3.SG for good not

'(Him) frequently taking showers is not good for Ali's bathroom.'

In (28a), Ali from inside the possessive phrase Ali'nin saçlarl 'Ali's hair' can control the PRO subject in the subject infinitive, as saç hair is an example of an inalienably possessed noun. On the other hand, this is not possible in (28b) as banyo 'bathroom' is not in this category. Expectedly, if the structure of the infinitive changes from control to no-control, the empty subject small pro can exhaustively refer to Ali, as given in (29).
[pro ${ }_{i}$ sik sik duş al-ma-si]
$\mathrm{Ali}_{\mathrm{i}}$-nin banyo-su
için iyi değil.
frequently shower take-INF-POSS.3.SG Ali-GEN bathroom-POSS.3.SG for good not
'(Him) frequently taking showers is not good for Ali's bathroom.'

4.2. [+HuMAN] AND TOPIC. Again in accordance with Landau (2013)'s claim, non-human DPs cannot control the PRO in a subject infinitive in Turkish. As shown in the Turkish counterpart of (22) in (30) below, even when it is introduced as a topic, for the non-human DP çizmeler 'boots' to control the empty subject inside the subject infinitive, the control version is not acceptable while the no control version is (30a-b).

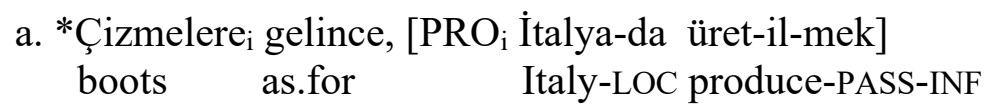



değer-ler-in-i arttır-1r.
value-PL-POSS.3.PL-ACC increase-AOR.3.SG
b. Çizmelere ${ }_{i}$ gelince, [pro İtalya-da üret-il-me-leri] ....
'As for the boots, (them) being produced in Italy increases their value.'

This shows that Turkish behaves similarly to English in terms of requiring the controller of the PRO subject of the subject infinitival clause to be a [+human] DP.

4.3. TOPIC VS. LOGOPHORIC CENTER. As we have seen in (4-5), repeated here as (31-32), subject infinitives in Turkish and English differ with respect to their choice of the controller for a subject infinitive between two candidates: the topic and the logophoric center. As in (31), there are three possible readings based on which R-expression(s) get(s) to control the PRO in English: i) Mary, as the sentence topic, can be the controller, ii) her teammate John, as the logophoric center of the upsetting event can be the controller, or iii) the two DPs, Mary and John, can control the PRO under split control.

(31) As for Maryi, $\left[\mathrm{PRO}_{\mathrm{i} / \mathrm{j}(+\mathrm{i})}\right.$ quitting the race] upset her teammate $\mathrm{John}_{\mathrm{j}}$.

On the other hand, in the Turkish counterpart of (31) given in (32), the sentence topic Ayşe cannot exhaustively control the PRO subject while the other two readings where the controller is only be the logophoric center Ali or both DPs control the PRO under split control are possible.

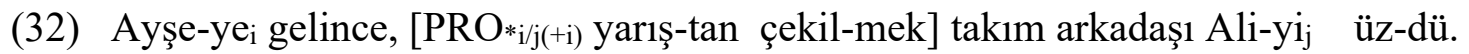
Ayşe-dat as.for race-ABL quit-INF team mate Ali-ACC upset-PST.3.SG 'As for Ayşe, (him/them) quitting the race upset her teammate Ali.'

Crucially, the sentence topic Ayşe can exhaustively co-refer to the empty subject if the structure changes to no-control, which also changes the empty subject to small pro, as given in (6) repeated here as (33).

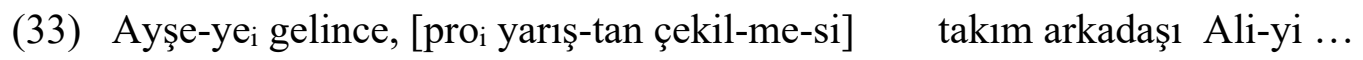 Ayşe-dat as.for race-ABL quit-INF-POSS.3.SG team mate Ali-ACC 'As for Ayşe, (her) quitting the race upset her teammate Ali.'

To conclude, this split in the antecedents of the two empty categories in Turkish, as opposed to English, supports the UPro approach in McFadden and Sundaresan (2016). On the other hand, it suggests a typological division between pro-drop languages like Turkish and non-pro-drop languages like English in terms of the role of topics and logophoric centers non-obligatorily controlling the PRO in a subject infinitive.

5. Predictions and Conclusion. The mechanism that I put forward here predicts that in a structure with a subject infinitival clause, if the matrix predicate is a psych-verb, and thus it introduces a logophoric center, a control structure with a PRO subject that is co-referential with the logophoric center is preferred to a pro subject as in (34-35) 1 .
$\left[\mathrm{PRO}_{\mathrm{i}}\right.$ şarkı mırıldan-mak] ben $_{\mathrm{i}-\mathrm{i}}$ çok rahatlat-tı. song hum-INF I-ACC a.lot relax-PST.3.SG 'Singing softly really relaxed me.'

\footnotetext{
1 There is speaker veriation when the controller is in 3rd person singular: a group of speakers do not get a contrast between a control versus a no-control structure.
} 
(35) [*proi şarkı mırıldan-ma-m] ben $\mathrm{i}_{\mathrm{i}} \mathrm{i}$ çok rahatlat-tı.

song hum-INF-POSS.1.SG I-ACC a.lot relax-PST.3.SG

'My singing softly really relaxed me.'

To conclude, I claim the data on Turkish subject infinitives covered here makes the following contributions to the literature with respect to the three approaches of control that I briefly summarized in this paper:

(36) a. Contra Boeckx et. al. (2010), the control relation observed between the direct object and the empty subject inside the subject infinitive in Turkish is better accounted for under a theory not based on movement.

b. Turkish data support the pragmatic analysis of Landau (2013). However, as a pro-drop language for the subject, topicality is only relevant for pro while being [+human] and the logophoric center are relevant for NOC PRO.

c. The distribution of pro and NOC PRO in Turkish subject infinitives provides supporting evidence for the UPro approach proposed in McFadden and Sundaresan (2016). However, the environment where pro appears is non-finite but agreement bearing embedded clauses, which is different than the 'typical finite clauses' that they identify.

\section{References}

AnderBois, Scott. 2014. The semantics of sluicing: Beyond truth conditions. Language 90(4). 887-926. https://doi.org/10.1353/lan.2014.0110.

Claus, Berry, A. Marlijn Meijer, Sophie Repp \& Manfred Krifka. 2017. Puzzling response particles: An experimental study on the German answering system. Semantics and Pragmatics 10(19). 1-51. https://doi.org/10.3765/sp.10.19.

Chomsky, Noam. 1986. Knowledge of language. New York: Praeger.

Christiansen, Bethany J. \& Brian D. Joseph. 2016. On the relationship between argument structure change and semantic change. Proceedings of the Linguistic Society of America (PLSA) 1. 26:1-11. https://doi.org/10.3765/plsa.v1i0.3726.

Haspelmath, Martin. 1993. More on the typology of inchoative/causative verb alternations. In Bernard Comrie \& Maria Polinsky (eds.), Causatives and transitivity. 87-120. Amsterdam: John Benjamins.

Silk, Alex. 2012. Modality, weights, and inconsistent premise sets. Semantics and Linguistic Theory (SALT) 22. 43-64. https://doi.org/10.3765/salt.v22i0.2641.

$\mathrm{Yu}$, Alan C. L. 2003. The morphology and phonology of infixation. Berkeley, CA: University of California dissertation. 